\title{
Human oocyte-cumulus complexes stimulate the human acrosome reaction*
}

\author{
Caroline E. Stock $\uparrow$, R. Bates $\dagger$, K. S. Lindsay $\dagger$, D. K. Edmonds $\dagger$ and \\ Lynn R. Fraser $\ddagger$
}

Chelsea Hospital for Women, Dovehouse Street, London SW3 6LT, UK; and $\ddagger$ Department of Anatomy \& Human Biology, King's College London, Strand, London WC2R 2LS, UK

\begin{abstract}
Summary. Oocyte-cumulus complexes were obtained, after induced ovulation, from infertile patients participating in an in-vitro fertilization programme. About $6 \mathrm{~h}$ after retrieval and depending on the expansion of the cumulus, 100000 motile spermatozoa, prepared by a migration-centrifugation method, were added. After $14-18 \mathrm{~h}$ incubation at $37^{\circ} \mathrm{C}$, oocytes were examined for signs of fertilization (pronuclei and polar body formation) and then removed; spermatozoa remaining in the incubation medium were fixed for transmission electron microscopy. To provide an adequate number of cells for observation, spermatozoa from a minimum of 3-5 oocytes from the same patient were pooled. When sufficient spermatozoa were available after insemination, the remainder of the suspension was incubated at $37^{\circ} \mathrm{C}$ and fixed along with the corresponding oocyte-incubated sample. In all, 32 sperm samples were assessed and fertilized oocytes were obtained with 29 of these. In the 24 samples in which $>100$ spermatozoa (mean of 192) could be assessed, $32 \%$ of spermatozoa had initiated or completed the acrosome reaction. In the 15 of these 24 samples for which oocyte-free controls were available, $31 \%$ of cells were reacting or reacted, compared with $15 \%$ of cells $(P<0.001)$ in the controls. In the remaining 8 samples, incubated with oocyte-cumulus complexes, $<100$ but $\geq 20$ spermatozoa (mean of 42 ) were assessed and again $32 \%$ of spermatozoa were reacted. Therefore, our results indicate that the acrosome reaction response observed in the presence of oocyte-cumulus complexes is approximately twice that observed in their absence. We conclude that some component of the complex stimulates the acrosome reaction in human spermatozoa.
\end{abstract}

Keywords: oocyte-cumulus complex; in-vitro fertilization; acrosome reaction; human

\section{Introduction}

Spermatozoa once released from the male genital tract undergo complex intracellular and surface modifications called capacitation which are time-dependent and prepare the spermatozoa for the acrosome reaction (AR). Capacitation and the AR, which results in release of lytic enzymes that assist penetration of the oocyte investments, are prerequisites for fertilization (Fraser \& Ahuja, 1988). Although the site where the AR occurs is still uncertain, there is considerable evidence that molecules emanating from the oocyte and/or its investments can stimulate the AR in mammalian spermatozoa (Meizel, 1985). The mammalian follicular oocyte is comprised of the cumulus oophorus, consisting of loosely connected cells with fluid contained within its interstices and the inner, tightly adherent corona radiata which surrounds the non-cellular zona pellucida. Fertilization

*Correspondence and reprint requests to Dr Lynn R. Fraser.

†Present address: Queen Charlotte's Maternity Hospital, Goldhawk Road, London W6 0XG, UK. 
requires penetration of both the cellular and non-cellular layers by spermatozoa in order to reach the plasma membrane of the oocyte. Ultrastructural studies of the penetration of spermatozoa through the oocyte investments indicate that the AR can occur in the cumulus cell mass as well as at the zona pellucida (Yanagimachi, 1981; Bedford, 1983; Chen \& Sathananthan, 1986).

The development of in-vitro fertilization systems has enabled fertilizing conditions to be manipulated and specific requirements to be investigated. The success of these systems has proved that the female genital tract is not obligatory; furthermore, fertilization can occur even in the total absence of oocyte investments, including the zona pellucida. Despite this, investments are present in vivo and evidence indicates that the human $\mathrm{AR}$ can be initiated by factors associated with follicles and follicular oocytes (see 'Discussion'). In the present study we have used transmission electron microscopy (EM) to assess the AR in human spermatozoa incubated with oocyte-cumulus complexes for 14-18 hand, when possible, compared these values with those obtained from aliquants of the same suspensions incubated in the absence of oocyte-cumulus complexes. The latter were obtained after an induced ovulation from infertile patients who were participating in an in-vitro fertilization programme. A preliminary report of this study has been presented in abstract form (Stock et al., 1988).

\section{Materials and Methods}

Induction of ovulation. Clomiphene ( $50 \mathrm{mg}$; Serophene: Serono Ltd, Welwyn Garden City, Herts, UK) and Pergonal (Serono Ltd) equivalent to 150 i.u. FSH were administered intramuscularly (i.m.) to patients from Days 3 to 7 of their cycle. Follicular growth was monitored daily by ultrasonography and measurement of serum oestradiol from Day 8 onwards. In cycles in which there were $\geq 3$ follicles with a diameter of $>12 \mathrm{~mm}$, with that of the leading follicle being at $\geq 16 \mathrm{~mm}$, an i.m. injection of 5000 i.u. human chorionic gonadotrophin (hCG) was administered. Laparoscopic oocyte retrieval was scheduled for $35 \mathrm{~h}$ later. Recovered oocytes were graded according to maturity as judged by expansion of the corona-cumulus complex and presence or absence of a first polar body. Oocyte-cumulus complexes were then incubated in modified Earle's medium (Gibco Ltd, Cowley, Oxford, UK) with added gentamicin and $10 \%$ heat-inactivated maternal serum at $37^{\circ} \mathrm{C}$ until insemination.

Sperm preparation. Semen samples were obtained immediately after successful retrieval of oocyte-cumulus complexes and allowed to liquefy for $30 \mathrm{~min}$. A motile sperm suspension was prepared by a migration centrifugation method. Briefly, 0.5-1.0 ml of semen was placed in 2-4 culture tubes (Falcon Plastics, Becton Dickinson UK Ltd, Cowley, Oxford, UK) and 1-1.5 ml Earle's medium (as above) were layered on top, minimizing disturbance of the interface. The tubes were incubated at $37^{\circ} \mathrm{C}$ for $30-45 \mathrm{~min}$ and the upper $0.5-1.0 \mathrm{ml}$ was removed and centrifuged at $500 \mathrm{~g}$ for $5 \mathrm{~min}$; the sperm pellet was then resuspended in $1 \mathrm{ml}$ fresh medium. The final concentration of actively motile spermatozoa was adjusted to $1 \times 10^{6}$ cells $/ \mathrm{ml}$.

Insemination. Insemination of oocyte-cumulus complexes was carried out $5-7 \mathrm{~h}$ after their retrieval $(40-42 \mathrm{~h}$ after hCG). A volume of $0.1 \mathrm{ml}$ sperm suspension containing $1 \times 10^{6}$ cells $/ \mathrm{ml}$ was added to each oocyte in $0.9 \mathrm{ml}$ medium, giving a final concentration of $1 \times 10^{5} / \mathrm{ml}$. Immature oocytes showing little expansion of the cumulus after 5-7 $\mathrm{h}$ were excluded from this study. Examination for signs of fertilization (pronuclei and second polar body formation) was carried out 14-18 h after insemination. Oocytes were then removed and the spermatozoa remaining in the medium were fixed for EM.

To provide control samples, any remaining sperm suspension was diluted with Earle's medium to produce a final concentration of $10^{6} \mathrm{cells} / \mathrm{ml}$ and incubated at $37^{\circ} \mathrm{C}$ overnight before fixation at the same time as the oocyte-incubated samples. Preliminary studies revealed no obvious differences in AR between samples with $10^{5}$ and $10^{6} \mathrm{cells} / \mathrm{ml}$ (unpublished observation). Since the latter were easier to process for EM, the higher concentration was used for the oocyte-free controls.

Electron microscopy and assessment. The sperm suspensions were fixed in an equal volume of $3 \%$ glutaraldehyde in $0.1 \mathrm{~m}$-cacodylate buffer, $\mathrm{pH} 7 \cdot 2$, for $1 \mathrm{~h}$. After fixation, samples were centrifuged at $600 \mathrm{~g}$ for $5 \mathrm{~min}$ and the sperm pellet was resuspended in fresh cacodylate buffer. To provide an adequate number of cells for EM assessment, spermatozoa from a minimum of 3-5 oocyte-cumulus complexes from the same patient were pooled. Samples were centrifuged at $600 \mathrm{~g}$ for $5 \mathrm{~min}$ and the pellet was fixed for $30-45 \mathrm{~min}$ in $0 \cdot 1 \%$ osmium tetroxide, then washed in $50 \%$ alcohol. The pellet was 'blocked' in molten agar (2\%), dehydrated through a series of graded alcohols and embedded in araldite resin. Ultra-thin sections were cut with a glass knife, stained with uranyl acetate and lead citrate and examined with a Philips $301 \mathrm{G}$ or Hitachi HU12A electron microscope.

Individual cells were classified into one of the 6 stages of the acrosome reaction which we have previously described (Stock \& Fraser, 1987). Stage 1 spermatozoa are unreacted, acrosome-intact cells, Stage 2-4 cells are at intermediate stages and Stages $5+6$ spermatozoa are acrosome-reacted. During the intermediate stages, swelling and 
loss of the acrosomal matrix occur while the plasma and outer acrosomal membranes appear to remain intact; the vesicles which form appear to be derived primarily from the outer acrosomal membrane. Only morphologically normal sperm heads were counted.

Statistical evaluation. The data were analysed using Cochran's modification of the $2 \times 2$ contingency tables (Snedecor \& Cochran, 1967).

\section{Results}

A total of 32 sperm samples provided sufficient numbers of cells for EM assessment after incubation with oocyte-cumulus complexes. Fertilization was observed in 29 of the 32 suspensions $(90.6 \%)$ and, in most, the majority of oocytes were fertilized. Sperm motility, examined at the end of the incubation period, was maintained in all samples.

In 24 of the 32 samples, $>100$ spermatozoa from the insemination dishes could be assessed (mean of 192 cells, range of 104-313) and the percentage of cells undergoing or having completed the AR was $31.6 \pm 3.6 \%$ (mean \pm s.e.m.). In the 15 of these 24 samples for which there were oocyte-free controls this value was $30.5 \pm 4.9 \%$, based on a mean of 186 cells per sample (range 104-313). In the 15 corresponding controls, a mean of 237 cells was examined (range of 187-286) and $14.5 \pm 2.8 \%$ were reacting or fully reacted (Fig. 1); this response was significantly lower than in the oocyte-incubated counterparts $(P<0.001)$. In the remaining 8 of the 32 oocyte-incubated samples, $<100$ but $\geq 20$ spermatozoa were assessed (mean of 42 cells and range of 20-77) and $31.4 \pm 7.6 \%$ of cells were reacting or fully reacted. In all groups, approximately half of the responding cells were at intermediate stages and half were fully reacted. Very similar levels of response were observed in all oocyte-incubated samples, whether many or few cells could be assessed and whether or not controls were available: $15 \%$ at Stages $2-4$ and $15-16 \%$ at Stages $5+6$. In contrast, the response in oocyte-free controls was much lower: $8 \%$ at Stages $2-4$ and $7 \%$ at Stages $5+6$.

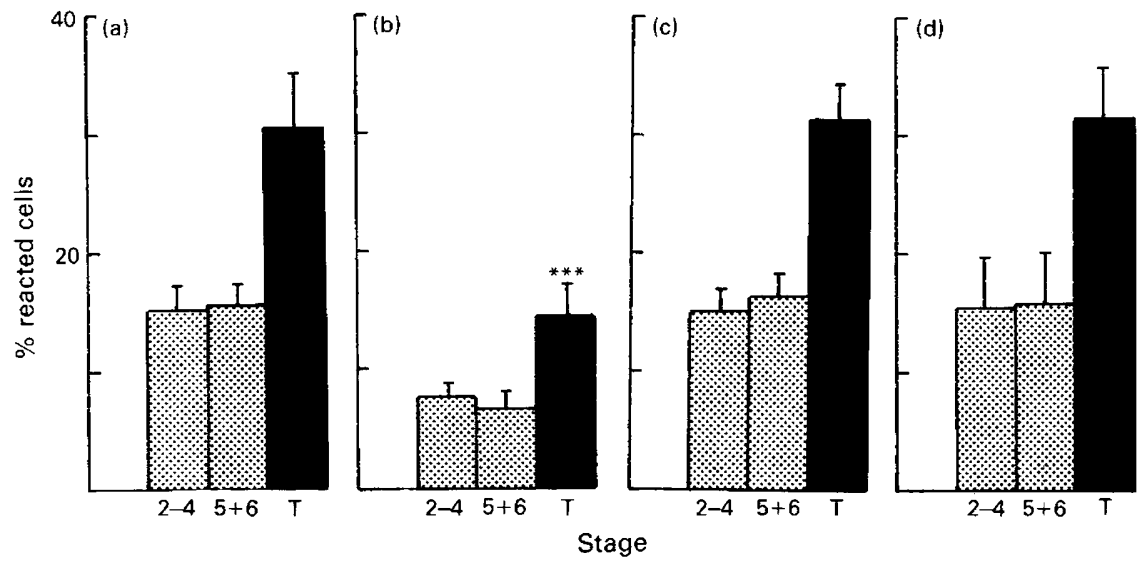

Fig. 1. AR response in human sperm suspensions incubated in the presence or absence of oocyte-cumulus complexes (OCC): (a) OCC-incubated suspensions which have OCC-free controls $(n=15)$; (b) OCC-free control suspensions $(n=15)$; (c) all OCC-incubated suspensions with $>100$ cells assessed $(n=24)$; (d) OCC-incubated suspensions with $<100$ cells assessed $(n=8)$. Values are presented as mean $\% \pm$ s.e.m. The stippled bars represent the proportions of cells at intermediate Stages $2-4$ and reacted Stages $5+6$; the solid bars $(T)$ represent the total mean \% reacted cells (Stages $2-6$ ). ${ }^{* * *} P<0.001$ compared with OCC-incubated counterparts (Fig. 1a). 
Spermatozoa were occasionally seen associated with or inside cumulus cells which had been fixed along with the sperm samples. The majority of these were acrosome-reacted and some of the engulfed cells were at an early stage of degeneration. Figure 2 shows one such spermatozoon. Degenerating sperm cells have rarely been seen in this or earlier studies in oocyte-free samples. These spermatozoa were excluded from statistical analysis.

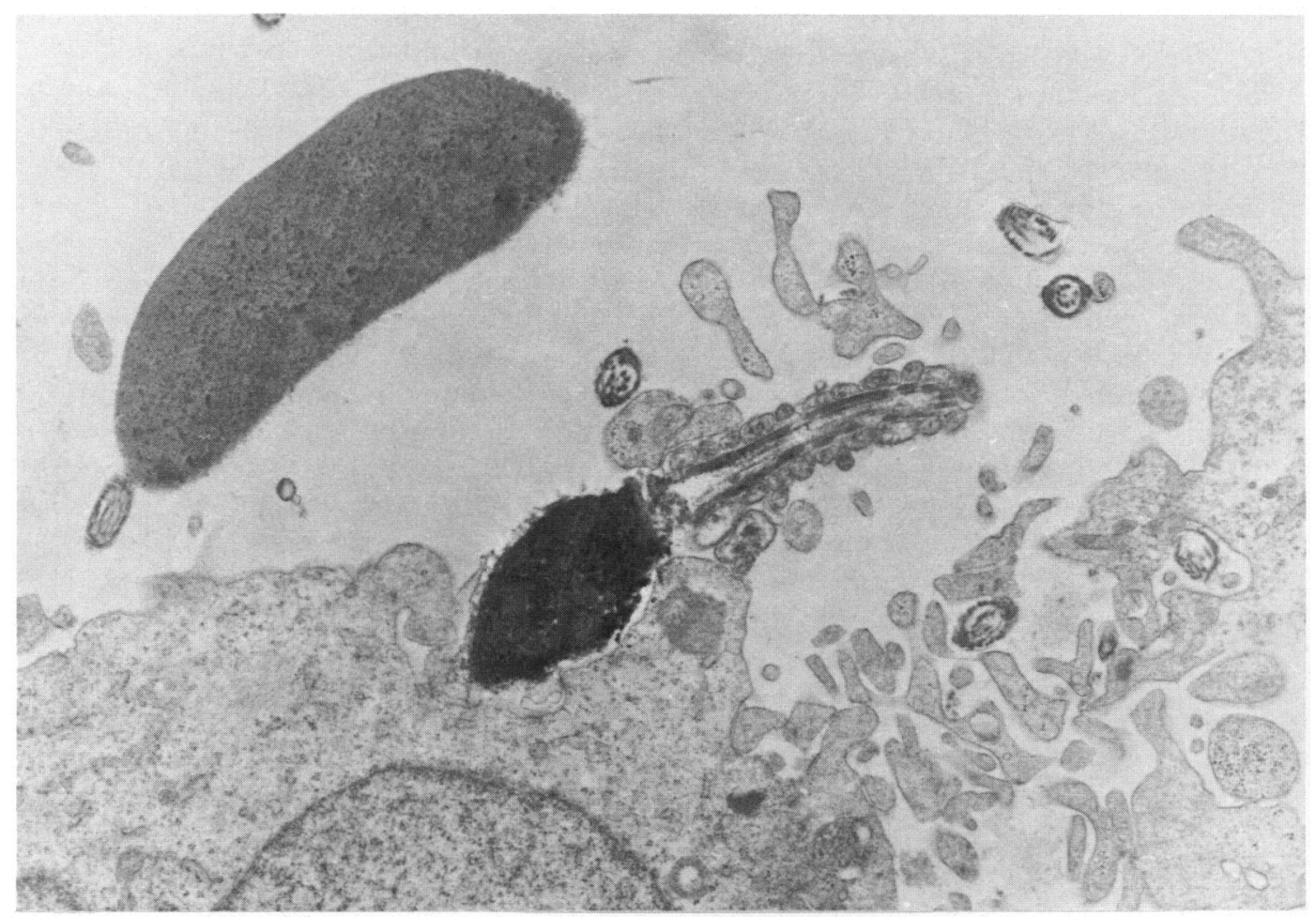

Fig. 2. Degenerating spermatozoon at early stage of engulfment by cumulus cell. $\times 9000$.

\section{Discussion}

The results obtained in the present study demonstrate that the human oocyte-cumulus complex can markedly and significantly stimulate the human sperm AR. Incubating spermatozoa with oocytes for $14-18 \mathrm{~h}$ resulted in $32 \%$ of the cells undergoing or having completed the AR, a significant increase $(P<0.001)$ when compared with controls. In the latter, incubated without oocytes, a relatively low incidence (15\%) of the AR was observed. These results are of particular interest since the majority of oocytes incubated with 29 out of the $32(91 \%)$ sperm samples evaluated were fertilized.

Although few comparable studies have been carried out, De Jonge et al. (1988), using the triple stain technique, have recently reported that the incidence of reacted spermatozoa in the presence of oocyte-cumulus complexes $(32 \%)$ was significantly higher than that in medium alone $(19 \%)$. These values are very similar to those of the present report. In an ultrastructural study of early timed penetration of human spermatozoa through the investments of human oocytes in vitro, Chen \& Sathananthan (1986) found that after $1 \mathrm{~h} 10-30 \%$ of the cells had undergone an AR and after a further $2-3 \mathrm{~h}$ this had risen to $30-60 \%$. Spermatozoa penetrating the cumulus were either intact or 
partly reacted, all stages of the AR were seen on the surface of the zona, and only reacting or reacted cells were observed penetrating the zona. In contrast to these relatively high incidences, two other studies using the triple stain technique found no evidence that oocytes are stimulatory. Evaluating only 5 samples, Plachot et al. (1984) reported that preincubated sperm suspensions subsequently incubated for $17 \mathrm{~h}$ with oocytes did not have an increased proportion of reacted live cells $(7 \%$ vs $8 \%$ for the controls). In a larger study of 183 samples, Boyers et al. (1987) preincubated suspensions for 6-8 h, then incubated them with oocytes in the presence or absence of heparin. The glycosaminoglycan heparin has been suggested to act as an initiator of the AR at the site of fertilization in vivo (Meizel, 1985). No significant differences were found between the two groups with respect to AR, fertilization or cleavage rates. Moreover, only $1-4 \%$ of spermatozoa were classified as reacted after $20-26 \mathrm{~h}$ incubation in vitro. These very low incidences of AR contrast sharply with those that we (present study), De Jonge et al. (1988) and Chen \& Sathananthan (1986) have observed.

Since our assessments were based on ultrastructural observations, it is appropriate to comment briefly on these. At present there is some conflict in the literature regarding the features of the human sperm AR, relative to the generalized pattern of the mammalian sperm AR. The latter is described as involving fusion between the plasma and outer acrosomal membranes, leading to vesiculation of the acrosomal cap and then exposure of the inner acrosomal membrane (Bedford, 1983). Some recent ultrastructural studies of human spermatozoa have suggested that the intermediate vesiculation stages involve the outer acrosomal membrane alone, not in conjunction with the plasma membrane (Nagae et al., 1986; Stock \& Fraser, 1987), while others suggest that human spermatozoa conform to the generalized reaction pattern (Yudin et al., 1988). Although a co-author of the Nagae et al. (1986) study, Yanagimachi (1988) has suggested that evaluation of cells penetrating the oocyte-cumulus complex is required. In their study of human spermatozoa interacting with oocytes, Chen \& Sathananthan (1986) stated that the typical mammalian AR was observed; however, their micrographs are of stages equivalent to those we have designated as acrosome-intact Stage 1 and reacted Stages 5 (vesicles present) and 6 (vesicles absent). While we were unable to duplicate their approach, for ethical reasons, the spermatozoa we assessed were obtained from the suspensions in which fertilization had occurred and therefore we believe that these AR were 'physiological'. Since the same stages, intermediate and reacted, were observed in the suspensions incubated with oocytes as in those incubated without, we have no grounds for altering our views that the $A R$ in human spermatozoa does differ from the conventional pattern.

Our observation of sperm engulfment by cumulus cells is consistent with other studies in which similar features have been noted (Soupart \& Strong, 1974; Chen \& Sathananthan, 1986). Its significance is not understood, although it might provide a mechanism for reducing sperm numbers and hence polyspermy or for removing defective spermatozoa.

Although the number of studies on human gamete interaction is limited, the establishment of numerous in-vitro fertilization programmes has made possible the evaluation of specific components of the follicle and oocyte-cumulus complex on the incidence of the AR in human spermatozoa. Mural granulosa cells, follicular fluid, cumulus cells with and without entrapped follicular fluid and zonae pellucidae have been examined. All have been demonstrated to exert a stimulatory effect, consistent with our findings. Table 1 summarizes recent results on the effects of these elements, as well as oocyte-cumulus complexes, on the human AR. Siiteri et al. (1988a) have reported that a short ( $20 \mathrm{~min}$ ) exposure to the first two washes of human cumulus cell fragments resulted in a 4-fold increase in AR, relative to controls, in human spermatozoa preincubated for $24 \mathrm{~h}$; the third wash was ineffective. However, medium in which washed preovulatory human mural granulosa and cumulus cells had been cultured was able to elicit this increased AR response. The active factor produced by these cultures appeared to have the same molecular weight and properties as an ARinducing component of follicular fluid (Siiteri et al., 1988b; Yudin et al., 1988), leading Siiteri et al. (1988a) to propose that the active factor in follicular fluid is produced and released by cumulus and granulosa cells. Tesarik (1985) reported that a $1-h$ incubation of human spermatozoa, preincubated 
for 5 and $15 \mathrm{~h}$, with washed cumulus cells or human follicular fluid resulted in an increased AR response. We have also found that human follicular fluid can stimulate the AR response, but only when present for an extended period of $>6 \mathrm{~h}$ (Stock et al., 1989). Depending on the concentration of follicular fluid present, the AR response was increased by a factor of $1.5(12.5 \%$ fluid) to 4 ( $100 \%$ fluid) over that of controls. Given the way oocyte-cumulus complexes were manipulated in the present study, the only follicular fluid present in the sperm-oocyte incubations would appear to be that trapped in the cumulus cells and therefore probably insufficient to account entirely for the observed effects of oocytes. Cross et al. (1988) have reported that the zona pellucida appears able to stimulate the AR in preincubated human spermatozoa. Incubation of sperm suspensions with cumulus-free non-viable (immature) oocytes or acid-disaggregated zonae for $1 \mathrm{~h}$ led to an appreciable increase in reacted cells, compared with control samples.

Table 1. Summary of recent studies of the effect of oocyte-associated components on the acrosome reaction (AR) in human spermatozoa

\begin{tabular}{lccccc}
\hline & Component* & $\begin{array}{c}\text { AR } \\
(\%) \dagger\end{array}$ & $\begin{array}{c}\text { Control } \\
\text { sample AR } \\
(\%)\end{array}$ & $\begin{array}{c}\text { Sperm } \\
\text { preincubation } \\
\text { Reference }\end{array}$ & $\begin{array}{c}\text { Exposure to } \\
\text { factor } \\
\text { (h) }\end{array}$ \\
\hline Present study & OCC & 32 & 15 & 0 & $14-18$ \\
De Jonge et al. (1988) & OCC & 32 & 19 & 0 & 16 \\
Chen \& Sathananthan (1986) & OCC & $30-60$ & - & $<1$ & $2-3$ \\
Plachot et al. (1984) & OCC & 8 & 7 & 5 & 17 \\
Boyers et al. (1987) & OCC & 1 & 2 & $6-8$ & $14-18$ \\
Tesarik (1985) & Cumulus & 43 & 27 & 15 & 1 \\
Siiteri et al. (1988a) & Cumulus & 46 & 11 & 24 & 20 min \\
Cross et al. (1988) & ZP & 46 & 4 & $5-7$ & 1 \\
Tesarik (1985) & FF 50\% & 42 & 27 & 15 & 1 \\
Suarez et al. (1986) & FF 50\% & 43 & 7 & 10 & 12 min \\
Mortimer \& Camenzind (1988) & FF 50\%/100\% & $26 / 27$ & 22 & 6 & 2 \\
Stock et al. (1989) & FF 50\% & 16 & 15 & 24 & 1 \\
Yudin et al. (1988) & FF 50\%/100\% & $38 / 54$ & 14 & 0 & 24 \\
& FF 50\% & 48 & 6 & 6 & 3 min \\
\hline
\end{tabular}

*OCC, oocyte-cumulus complex; ZP, zona pellucida; FF, follicular fluid.

$†$ Mean maximum response to the components in each study.

Results obtained in animal studies are consistent with the above findings in that fertilization rates are often higher in the presence than absence of cumulus cells. An early investigation by Gwatkin et al. (1972) found that the presence of hamster cumulus cells increased the proportion of fertilized hamster oocytes. Cultured bovine granulosa cells were able to replace the hamster cumulus cells, but only when present in 10 -fold increased numbers. Further evidence for a positive effect of cumulus cells in the hamster was provided by Bavister (1982). Fertilization rates were low when oocyte-cumulus complexes were washed or when the total volume of medium used was increased, thereby presumably diluting any stimulatory components. There is also evidence that the zona pellucida can stimulate or initiate the AR in several other mammalian species (guinea-pig: Myles et al., 1987; hamster: Cherr et al., 1986; mouse: Saling \& Storey, 1979; Bleil \& Wassarman, 1983; rabbit: O'Rand \& Fisher, 1987).

While it is true that cumulus cells, follicular fluid and the zona pellucida have been shown capable of stimulating or initiating the AR in humans and other mammals, investments do not appear to be obligatory for fertilization. Oocytes devoid of the cumulus cells and/or the zona pellucida can be equally or even more readily penetrated by spermatozoa than their cumulus and zona-intact counterparts (e.g. rabbit: Fraser et al., 1971; mouse: Fraser, 1983). Despite this, our results indicate that, although the mean incidence of spontaneous AR in human spermatozoa even after an extended incubation in vitro of up to $24 \mathrm{~h}$ is quite low ( $<20 \%$ : present study; Stock \& Fraser, 1987), this response can be markedly increased by exposure to elements of the 
oocyte-cumulus complex. This suggests that, while the oocyte investments might not be obligatory, the presence of stimulatory molecules may represent a mechanism for maximizing the possibility that potentially fertilizing spermatozoa undergo the AR in the immediate vicinity of the oocyte, rather than at random within the female tract.

We thank Paul Fielding for expert technical assistance, Andrew Osborne for the artwork; and Leon Kelberman for the photographic prints. This study was supported by a grant from Birthright to L.R.F.

\section{References}

Bavister, B.D. (1982) Evidence for a role of post-ovulatory cumulus components in supporting fertilizing ability of hamster spermatozoa. J. Androl. 3, 365-372.

Bedford, J.M. (1983) Significance of the need for sperm capacitation before fertilization in eutherian mammals. Biol. Reprod. 28, 108-120.

Bleil, J.D. \& Wassarman, P.M. (1983) Sperm-egg interactions in the mouse: Sequence of events and induction of the acrosome reaction by a zona pellucida glycoprotein. Devl Biol. 95, 317-324.

Boyers, S.P., Tarlatzis, B.C., Stronk, J.N. \& DeCherney, A.H. (1987) Fertilization and cleavage rates of heparin-exposed human oocytes in vitro, and the effect of heparin on the acrosome reaction. Fert. Steril. 48, 628-632.

Chen, C. \& Sathananthan, A.H. (1986) Early penetration of human sperm through the vestments of human eggs in vitro. Archs Androl. 16, 183-197.

Cherr, G.N., Lambert, H., Meizel, S. \& Katz, D.F. (1986) In vitro studies of the golden hamster sperm acrosome reaction: completion on the zona pellucida and induction by homologous soluble zonae pellucidae. Devl Biol. 114, 119-131.

Cross, N.L., Morales, P., Overstreet, J.W. \& Hanson, F.W. (1988) Induction of acrosome reactions by the human zona pellucida. Biol. Reprod. 38, 235-244.

De Jonge, C.J., Rawlins, R.G. \& Zaneveld, L.J.D. (1988) Induction of the human sperm acrosome reaction by human oocytes. Fert. Steril. 50, 949-953.

Fraser, L.R. (1983) Mouse sperm capacitation assessed by kinetics and morphology of fertilization in vitro. $J$. Reprod. Fert. 69, 419-428.

Fraser, L.R. \& Ahuja, K.K. (1988) Metabolic and surface events in fertilization. Gamete Res. 20, 491-519.

Fraser, L.R., Dandekar, P. \& Vaidya, R.A. (1971) In vitro fertilization of tubal rabbit ova partially or totally denuded of follicular cells. Biol. Reprod. 4, 229-233.

Gwatkin, R.B.L., Anderson, O.F. \& Hutchinson, C.F. (1972) Capacitation of hamster spermatozoa in vitro: the role of cumulus components. J. Reprod. Fert. 30, 389-394.

Meizel, S. (1985) Molecules that initiate or help stimulate the acrosome reaction by their interaction with the mammalian sperm surface. Am. J. Anat. 174, 285-302.

Mortimer, D. \& Camenzind, A.R. (1988) Follicular fluid does not induce the human sperm acrosome reaction in vitro. J. Reprod. Fert., Abstr. Ser. 1, 39, abstr.

Myles, D.G., Hyatt, H. \& Primakoff, P. (1987) Binding of both acrosome-intact and acrosome-reacted guinea pig sperm to the zona pellucida during in vitro fertilization. Devl Biol. 121, 559-567.

Nagae, T., Yanagimachi, R., Srivastava, P.N. \& Yanagimachi, H. (1986) Acrosome reaction in human spermatozoa. Fert. Steril. 45, 701-707.

O'Rand, M.G. \& Fisher, S.J. (1987) Localization of zona pellucida binding sites on rabbit spermatozoa and induction of the acrosome reaction by solubilized zonae. Devl Biol. 119, 551-559.

Plachot, M., Mandelbaum, J. \& Junca, A. (1984) Acrosome reaction of human sperm used for in vitro fertilization. Fert. Steril. 42, 418-423.

Saling, P.M. \& Storey, B.T. (1979) Mouse gamete interactions during fertilization in vitro. Chlortetracycline as a fluorescent probe for the mouse sperm acrosome reaction. J. Cell Biol. 83, 544-555.

Siiteri, J.E., Dandekar, P. \& Meizel, S. (1988a) Human sperm acrosome reaction-initiating activity associated with the human cumulus oophorus and mural granulosa cells. J. exp. Zool. 246, 71-80.

Siiteri, J.E., Gottlieb, W. \& Meizel, S. (1988b) Partial characterization of a fraction from human follicular fluid that initiates the human sperm acrosome reaction in vitro. Gamete Res. 20, 25-42.

Snedecor, G. \& Cochran, W. (1967) Statistical Methods, 6th edn. Lowa State University Press, Ames.

Soupart, P. \& Strong, P.A. (1974) Ultrastructural observations on human oocytes fertilized in vitro. Fert. Steril. 25, 1 I-44.

Stock, C.E. \& Fraser, L.R. (1987) The acrosome reaction in human sperm from men of proven fertility. Human Reprod. 2, 109-119.

Stock, C.E., Bates, R., Lindsay, K.S., Edmonds, D.K. \& Fraser, L.R. (1988) Human oocyte cumulus complexes enhance the human acrosome reaction. $J$. Reprod. Fert., Abstr. Ser. 2, 10, abstr.

Stock, C.E., Bates, R., Lindsay, K.S., Edmonds, D.K. \& Fraser, L.R. (1989) Extended exposure to follicular fluid is required for significant stimulation of the acrosome reaction in human spermatozoa. J. Reprod. Fert. 86, 401-411.

Suarez, S.S., Wolf, D.P. \& Meizel, S. (1986) Induction of the acrosome reaction in human spermatozoa by a fraction of human follicular fluid. Gamete Res. 14, 107-121.

Tesarik, J. (1985) Comparison of acrosome reactioninducing activities of human cumulus oophorus, follicular fluid and ionophore A23187 in human sperm populations of proven fertilizing ability in vitro. J. Reprod. Fert. 74, 383-388. 
Yanagimachi, R. (1981) Mechanisms of fertilization in mammals. In Fertilization and Embryonic Development in Vitro, pp. 81-182. Eds L. Mastroianni \& J. D. Biggers. Plenum Publishing, New York.

Yanagimachi, R. (1988) Mammalian fertilization. In The Physiology of Reproduction, Vol. 1, pp. 135-185. Eds E. Knobil, J. Neill, L. L. Ewing, C. L. Markert, G. S. Greenwald \& D. W. Pfaff. Raven Press, New York.
Yudin, A.I., Gottlieb, W. \& Meizel, S. (1988) Ultrastructural studies of the early events of the human sperm acrosome reaction as initiated by human follicular fluid. Gamete Res. 20, 11-24.

Received 22 December 1988 